\title{
A quebra da cadeia de custódia da prova e seus desdobramentos no processo penal brasileiro
}

\author{
Evidence chain of custody break and its effects \\ in the Brazilian criminal proceeding
}

\author{
Isabela Aparecida de Menezes ${ }^{\mathbf{1}}$ \\ Pontifícia Universidade Católica do Paraná - Londrina/PR \\ isamenezees@gmail.com \\ http://lattes.cnpq.br/3285149492979934 \\ http://orcid.org/0000-0002-3421-5136 \\ Luiz Antonio Borri² \\ Londrina/PR \\ luiz@advocaciabittar.adv.br \\ http://lattes.cnpq.br/1414046440611495 \\ (1.) http://orcid.org/0000-0001-7649-1270 \\ Rafael Junior Soares ${ }^{3}$ \\ Pontifícia Universidade Católica do Paraná - Londrina/PR \\ rafael@advocaciabittar.adv.br \\ http://lattes.cnpq.br/7645805665092232 \\ http://orcid.org/0000-0002-0035-0217
}

1 Graduanda do Curso de Direito da PUCPR - Campus Londrina/PR.

2 Possui graduação em Direito com láurea acadêmica pela Pontifícia Universidade Católica do Paraná Campus Londrina (2011). Atualmente é advogado Walter Barbosa Bittar \& Advogados Associados. Especialista em Direito e Processo Penal pela Universidade Estadual de Londrina. Pós-graduado em Direitos Fundamentais pelo IGC Coimbra e IBCCRIM. Pós-graduado em Ciências Criminais pela PUCPR Campus Maringá.

3 Possui graduação em Direito pela Universidade Estadual de Londrina - UEL (2007). Especialista em Criminologia e Política Criminal pelo ICPC-UFPR (2009). Especialista em Direito Penal Econômico e Europeu pelo IDPEE - Coimbra e IBCCRIM (2010). Atualmente é advogado - Walter Barbosa Bittar \& Advogados Associados. Professor de Direito Penal na Pontifícia Universidade Católica do Paraná - PUC/PR - Campus Londrina-PR (2013). 
Resumo: O presente artigo visa a abordar a quebra da cadeia de custódia da prova e seus desdobramentos no processo penal brasileiro. $\mathrm{O}$ tema tem ganhado cada dia mais importância a ponto de merecer exame mais aprofundado do seu significado e relevância como forma de garantir a confiabilidade da prova produzida no processo penal desde seu nascedouro até o momento da valoração pelo magistrado, permitindo-se a verificação de sua cronologia existencial. Além disso, deve-se explorar a base legal que regulamenta o instituto no âmbito nacional, a fim de verificar as consequências geradas a partir do desrespeito à cadeia de custódia à luz dos princípios constitucionais. Finalmente, pretende-se apontar os desdobramentos do desrespeito ou violação à cadeia de custódia da prova, incursionando nas implicações daí oriundas, especialmente a incidência de ilicitude da fonte de prova e sua repercussão nas provas derivadas.

Palavras-chave: Cadeia de custódia; confiabilidade da prova; ilicitude.

AвSTRACT: This article aims to address the evidence's custody chain breaks and its effects in the Brazilian criminal proceedings. Every day the theme has become more important to the point of deserving a deeper examination of its meaning and relevance as a way of guaranteeing the reliability of the evidence produced in the criminal process, from its inception until the moment of its evaluation by the court, allowing the verification of its existential chronology. Moreover, the legal basis governing the institute at a national level should be explored in order to verify the consequences of its disregarding in the light of the constitutional principles. Finally, the article seeks to point out the consequences of the disregard or violation of the evidence's custody chain, including the implications thereof, specially regarding the incidence of unlawfulness in the evidence's source and its repercussion in the derived evidences.

KEYwORDS: Evidence's custody chain; reliability of evidence; unlawfulness.

SumÁrıo: Introdução; 1. A cadeia de custódia. 2. O Código de Processo Penal e a legislação vigente no Brasil; 3. A ilicitude da prova em decorrência da quebra da cadeia de custódia; Conclusão; Referências. 


\section{INTRODUÇÃO}

A discussão travada no estudo em análise terá por objetivo debater acerca da quebra da cadeia de custódia da prova. Questiona-se: qual a consequência que a inobservância dos procedimentos legais ou do devido cuidado no momento da coleta, manipulação e transporte do objeto pode trazer para o elemento, que agora é prova, trazido em juízo?

Incialmente, objetivou-se explorar o significado do instituto, vez que embora o Superior Tribunal de Justiça já tenha se manifestado sobre o assunto no acórdão do Habeas Corpus nº. 160.662/RJ, a cadeia de custódia da prova não está devidamente regulamentada no ordenamento jurídico pátrio. Do mesmo modo, analisou-se a importância do instituto, notadamente porque a ausência de cuidado com o elemento produzido pela acusação repercute diretamente na garantia constitucional do réu ao devido processo legal.

Com efeito, por meio da análise dos princípios constitucionais, normas processuais penais e da jurisprudência nacional, pretendeu-se verificar a possibilidade de reconhecimento do instituto da cadeia de custódia no ordenamento brasileiro, como garantia ao acusado de que os elementos que instruem a acusação foram obtidos em observância aos procedimentos legais.

Finalmente, pretende-se explorar o resultado prático da quebra da cadeia de custódia, delimitando se a inobservância por parte do detentor da prova acerca do procedimento e cuidado devido acarreta a falta de confiabilidade do elemento probatório a ensejar sua ilicitude.

\section{A CADEIA DE CUSTÓDIA}

No processo penal a prova ${ }^{4}$ assume um papel deveras importante, já que “constituem os olhos do processo, o alicerce sobre o qual se ergue

4 O termo é polissêmico, conforme afirma Antonio Magalhães Gomes Filho, podendo ser apontada, sob a perspectiva jurídica, a seguinte classificação para tratar do tema prova: a) fonte de prova: pessoas ou coisas das quais se pode conseguir a prova; b) meios de prova: instrumentos por meios dos quais os dados probatórios são introduzidos e fixados no processo; c) meios de investigação de prova: são procedimentos regulados em lei que objetivam alcançar provas materiais, são marcados, geralmente, pelo elemento 
toda a dialética processual5". É por meio dela que o julgador exerce sua função e fundamenta as razões da decisão, sendo imprescindível que passe pelo crivo do contraditório ${ }^{6}$, ainda que diferido ${ }^{7}$. Com efeito, o contraditório consubstancia garantia fundamental do indivíduo caracterizada pela possibilidade de participação ativa nos assuntos que lhe tragam interesse e efetiva influência no procedimento formativo dos procedimentos, reduzindo a possibilidade de decisões surpresa no processo judicial ${ }^{8}$.

Dierle Nunes prossegue realçando que o contraditório constitui faculdade e não obrigação da parte e aponta dois modos de exercê-lo: a) preventivo, antecipado ou ex ante, consistindo naquele realizado no

surpresa, sobretudo porque o conhecimento da parte tornaria inviável a obtenção de fontes de prova. Sobre isso, ver: GOMES FILHO, Antonio Magalhães. Notas sobre a terminologia da prova (reflexos no processo penal brasileiro). In: YARSHELL, Flávio Luiz; MORAES, Maurício Zanoide de (orgs). Estudos em homenagem à professora Ada Pellegrini Grinover. São Paulo: DPJ Editora, 2005, p. 303-310.

5 CAPEZ, Fernando. Curso de processo penal. 19ª ed. São Paulo: Saraiva, 2012, p. 360.

6 "Evidente que a prova deve ser séria, ao menos sensata. Mais ainda: prova séria é aquela colhida sob o crivo do contraditório. Na hipótese de, na instrução, não ter sido feita nenhuma prova a respeito da autoria, não pode o Juiz louvar-se no apurado na fase inquisitorial presidida pela Autoridade Policial. Não que o inquérito não apresente valor probatório; este, contudo, somente poderá ser levado em conta se, na instrução, surgir alguma prova, quando, então, é lícito ao Juiz considerar tanto as provas do inquérito quanto aquelas por ele colhidas, mesmo porque, não fosse assim, estaria proferindo um decreto condenatório sem permitir ao réu o direito constitucional do contraditório (...).” (STF - AP 858/DF, Relator: Min. Gilmar Mendes, Voto: Min. Celso de Mello, Julgamento, 26.08.2014, $2^{\mathrm{a}}$ turma, Data da Publicação: Acórdão Eletrônico DJe-219 Divulg. 06-11-2014 Public. 07-11-2014).

7 "Os fundamentos da decisão que deferiu a escuta telefônica, além das decisões posteriores que mantiveram o monitoramento devem estar acessíveis à parte investigada no momento de análise da denúncia e não podem ser subtraídas da Corte, que se vê tolhida na sua função de apreciar a existência de justa causa da ação penal. Trata-se de um contraditório diferido, que permite ao cidadão exercer um controle sobre as invasões de privacidade operadas pelo Estado." (STF - Inq 2266, Relator Ministro Gilmar Mendes, Tribunal Pleno, julgamento em 26.5.2011, DJe de 13.3.2012).

8 NUNES, Dierle José Coelho. O princípio do contraditório: uma garantia de influência e de não surpresa. In: DIDIER JR, Fredie. (org.) Teoria do Processo - Panorama doutrinário mundial. 1 ed. Salvador: Juspodium, 2007, v.1, p. 152. 
procedimento formativo do provimento; e b) sucessivo, postecipado ou ex-post, conceituado como aquele manifestado após a prolação do provimento visando o controle e a eficácia deste. ${ }^{9}$

A partir daí deve se tomar o devido cuidado com as fontes de prova obtidas fora do processo, não apenas pela dificuldade do réu em contraditar tais elementos, mas também porque, na maioria das vezes, o acusado fica "nas mãos" do Estado-acusação, já que o elemento probatório, além de produzido pelo órgão acusador, fica sob seus cuidados. Desse modo, “o tema de provas exige a intervenção de regras de 'acreditação', pois nem tudo que ingressa no processo pode ter valor probatório; há que ser 'acreditado', legitimado, valorado desde sua coleta até a sua produção em juízo para ter valor probatório." ${ }^{10}$

Surge aí, o instituto da cadeia de custódia com o objetivo de garantir a todos os acusados o devido processo legal, bem como os recursos a ele inerentes, como a ampla defesa, o contraditório e principalmente o direito à prova lícita ${ }^{11}$. A cadeia de custódia abarca todo o caminho que deve ser percorrido pela prova até sua exata análise e escorreita inserção no processo, sendo que qualquer interferência durante o trâmite processual pode resultar na sua imprestabilidade. Desse modo, não se pode limitar a garantia constitucional da prova, isso porque deve abranger também "a possibilidade de se indicar fontes de prova, de se exigir que elas venham ao processo, da mesma forma como foram obtidas, de utilizar os mecanismos de prova, pela metodologia legalmente definida, e de exigir a valoração dos elementos trazidos". ${ }^{12}$

Nesse sentido, a cadeia de custódia pode ser definida como "uma sucessão de eventos concatenados, em que cada um proporciona a viabilidade ao desenvolvimento do seguinte, de forma a proteger a integridade de um vestígio do local de crime ao seu reconhecimento como prova

9 Ibidem, p. 164-165.

LOPES JR., Aury. Direito Processual Penal. 14a . ed. São Paulo: Saraiva, 2017, p. 412 .

11 Artigo $5^{\circ}$, inciso LVI: "são inadmissíveis, no processo, as provas obtidas por meios ilícitos".

12 EDINGER, Carlos. Cadeia De Custódia, Rastreabilidade Probatória. Revista Brasileira de Ciências Criminais, vol. 120, p. 237-257, mai.-jun./2016. p. 244. 
material até o trânsito em julgado do mérito processual." ${ }^{13}$ Noutras palavras, a cadeia de custódia é considerada uma sucessão "de elos, que dizem respeito a um vestígio que, por sua vez, eventualmente, será considerado uma prova. Um elo é qualquer pessoa que tenha manejado esse vestígio. É dever do Estado - e, também, direito do acusado, identificar, de maneira coerente e concreta, cada elo, a partir do momento no qual o vestígio foi encontrado. Assim, fala-se em cadeia de custódia íntegra quando se fala em uma sucessão de elos provados"14.

Com isso, segundo Geraldo Prado, o instituto objetiva discutir a possibilidade concreta de manipulação indevida do elemento probatório, notadamente porque a cadeia de custódia da prova "leva em consideração questões de ordem prática como, por exemplo, a manipulação indevida do elemento probatório com o propósito de incriminar ou isentar alguém de responsabilidade e também interroga, no plano teórico, as condições concretas do melhor conhecimento judicial." ${ }^{15}$

Estabelecido o conceito de cadeia de custódia é relevante destacar que os problemas discutidos nesse opúsculo concentrar-se-ão na falta ou insuficiência de documentação da cadeia de custódia. Tal advertência é importante porque o fato de inexistir o registro das pessoas que mantiveram contato com a fonte de prova não significa assentir que houve violação da cadeia de custódia, isto porque "não se viola a sucessão de pessoas que teve contato com a coisa, mas a documentação que atesta essa realidade." 16

Insta salientar que o instituto não pretende colocar em dúvida a credibilidade da prova colhida pela autoridade policial, analisada por peritos ou de qualquer pessoa do Estado que tenha tido contato com o elemento

13 DIAS FILHO, Claudemir Rodrigues. Cadeia de custódia: do local de crime ao trânsito em julgado; do vestígio à evidência. In: MOURA, Maria Thereza Rocha de Assis; NUCCI, Guilherme de Souza (orgs). Doutrinas Essenciais Processo Penal. v. 3. São Paulo: RT, 2012. p. 404.

PRADO, Geraldo. Ainda sobre a "quebra da cadeia de custódia das provas". Boletim IBCCRIM, São Paulo, ano 22, no 262, set./2014, p. 16-17.

16 BADARÓ, Gustavo. A cadeia de custódia e sua relevância para a prova penal. In: SIDI, Ricardo; LOPES, Anderson B. Temas atuais da investigação preliminar no processo penal. Belo Horizonte: D’ Plácido, 2018, p. 524. 
probatório, mas garantir ao acusado que aquela prova possa ser acreditada, ou seja, "demonstre que tais objetos correspondem ao que a parte alega ser." ${ }^{17}$

Trata-se de assegurar ao acusado que o Estado cumprirá a obrigação de conservar a prova, a fim de garantir a sua integridade e confiabilidade, conceituando a doutrina ${ }^{18}$ como a "mesmidade", ou seja, a garantia de que a prova colhida é a mesma que a projetada em juízo. Aury Lopes Jr. e Alexandre da Rosa exemplificam a violação da "mesmidade" nas interceptações telefônicas, pois "a prova é 'filtrada' pela autoridade policial ou órgão acusador, que traz para o processo (e submete ao contraditório diferido) apenas o que lhe interessa. Não é 'a mesma' prova colhida, mas apenas aquela que interessa ao acusador, subtraindo o acesso da defesa". ${ }^{19}$

A cadeia de custódia da prova também deve observar o princípio da "desconfiança”, decorrência natural do Estado democrático de direito, vez que não se pode afirmar (com certeza) que o objeto discutido é aquilo que a parte afirma ser, o julgador não pode colocar confiança especial em uma parte, principalmente quando ela representa o Estado. Nesse sentido, o princípio da desconfiança é compreendido sob a perspectiva de que o objeto ou documento é insuficiente para representar aquilo que a parte diz que significa, ou seja, inexistiria confiança preestabelecida, de modo que ninguém, nem mesmo o magistrado teria motivo para depositar confiança em determinada parte. Tanto a acusação como a defesa são devidamente remuneradas para sustentar aquilo que defendem, implicando reconhecer que fora do mundo da prova, não há por que haver concessões para ninguém, incluindo até mesmo as proposições factuais que dizem que determinado objeto é o que digo que é. ${ }^{20}$

17 LOPES JUNIOR, Aury. Direito Processual Penal. 14ª . ed. São Paulo: Saraiva, 2017, p. 412.

18 PRADO, Geraldo. Ainda sobre a "quebra da cadeia de custódia das provas". Boletim IBCCRIM, São Paulo, ano 22, nº 262, p. 16-17, set./2014.

19 LOPES JUNIOR, Aury; ROSA, Alexandre Morais da. A importância da cadeia de custódia para preservar a prova penal. Disponível em: <https://www.conjur. com.br/2015-jan-16/limite-penal-importancia-cadeia-custodia-prova-penal>. Acesso em: 08 dez. 2017.

20 BAYTELMAN A., Andrés; DUCE J., Mauricio. Litigación penal: juicio oral y prueba. México: FCE, 2005, p. 283 apud PRADO, Geraldo. Ainda sobre a "quebra da cadeia de custódia das provas". Boletim IBCCRIM, São Paulo, ano $22, n^{\circ} 262$, set./2014, p.16-17. 
Desse modo, seja pela "mesmidade" ou pela "desconfiança", a ausência da observância de um procedimento específico no momento da produção do elemento probatório pode gerar a quebra da cadeia de custódia da prova e, por consequência sua ilicitude ${ }^{21}$. Sendo assim, necessário se faz que o detentor da fonte de prova, na maioria das vezes o Estado-acusação, tenha o devido cuidado na coleta, manipulação e transporte do objeto que, posteriormente, será um elemento probatório, a fim de preservar a cadeia de custódia e garantir a integridade da prova.

Acerca da integridade da prova, assinala Dias Filho que "por integridade entende-se o caráter daquilo que está inteiro, ileso, que não sofreu alteração, incólume, idôneo (...). Logo, além da integridade se soma os procedimentos necessários à manutenção das características intrínsecas do vestígio, qualquer que seja sua natureza (física, química, biológica, etc.). Diante deste raciocínio, é notório que se incluam critérios de coleta, transporte, acondicionamento, preservação e armazenamento como formas de garantir a integridade da prova. ${ }^{22}$ ".Com efeito, é importante salientar que a ausência de cuidado com a fonte de prova produzida repercute também no direito constitucional do devido processo legal e todos os meios e recursos a ele inerente (ampla defesa, contraditório, paridade de armas), vez que visa a garantir ao acusado condições de se defender e evitar arbítrios estatais ${ }^{23}$, ou seja, o instituto permite "avaliar se aquela prova que está no Tribunal, e que representa a materialidade de um ato criminoso, foi tratada com o devido rigor técnico-científico legal desde sua origem de colheita no local da infração penal”. ${ }^{24}$

21 “A prova cuja cadeia de custódia for quebrada será considerada ilícita ou ilegítima (distinção que, para mim, cientificamente, a partir da supremacia da Constituição ou da sua dimensão objetiva, pouco sentido faz). Assim, uma vez reconhecida sua ilicitude, de forma definitiva, haverá o desentranhamento e sua inutilização" (EDINGER, Carlos, Op. cit. p. 251).

DIAS FILHO, Claudemir Rodrigues. Op. cit. p. 403.

MORAES, Alexandre de. O devido processo legal e a vedação às provas ilícitas. Disponível em <https://www.conjur.com.br/2014-abr-11/justica-comentadadevido-processo-legal-vedacao-provas-ilicitas>. Acesso em 08 dez. de 2017.

CARVALHO, Jeferson Lemes. Cadeia de Custódia e Sua Relevância na Persecução Penal. Brazilian Journal of Forensic Sciences, Medical Law and Bioethics, vol. 05, p. 371-382, 2016. p. 373. 
Noutras palavras, o instituto da cadeia de custódia da prova é importante porque garante ao réu que todos os elementos que instruem a acusação foram obtidos em observância aos procedimentos legais, sobretudo porque, se assim não for, o Estado estará afrontando a garantia fundamental do indivíduo consubstanciada no devido processo legal, contraditório e ampla defesa. Do mesmo modo, pode acarretar "na falta de integridade da prova, provocando danos irrecuperáveis no material coletado, comprometendo a idoneidade do processo e prejudicando a sua rastreabilidade" 25

Nesse sentido, a cadeia de custódia da prova "traduz a necessidade de que se possibilite o efetivo contraditório, sendo dever do órgão acusador e da polícia judiciária a disponibilização de recursos e meios que, mais do que possibilitar mero acesso a elementos de prova, tragam conteúdo íntegro, coerente e consistente - que possa ser rastreado e verificado". ${ }^{26}$ Dessa forma, a quebra da cadeia de custódia, ou seja, a inobservância por parte do detentor da prova acerca do procedimento e cuidado devidos, seja no aspecto da correspondência entre a prova colhida e aquela trazida ao feito ("mesmidade"), ou mesmo na perspectiva do significado que a prova possui segundo as afirmativas de uma parte (desconfiança), acarreta a falta de confiabilidade do elemento probatório e, por consequência, sua ilicitude, impedindo a sua valoração ${ }^{27}$ no processo.

\section{O Código de Processo Penal e a legislação vigente no Brasil}

A cadeia de custódia da prova encontra fundamento em diversos dispositivos constitucionais, mormente a paridade de armas, presunção de inocência, devido processo legal ${ }^{28}$, ampla defesa e contraditório (art.

25 CARVALHO, Jeferson Lemes. Op. cit. p. 373.

26 EDINGER, Carlos. Op. cit. p. 254-255.

27 Segundo Gustavo Badaró "do ponto de vista material que poderá ser valorado para a formação do convencimento judicial, não terá maiores reflexos a distinção entre prova ilícita e prova ilegítima, na medida em que, tanto a prova obtida ilicitamente quanto a prova produzida ilegitimamente não poderá ser valorada pelo juiz." (Processo Penal. $4^{\text {a }}$. ed. São Paulo: RT, 2016, p. 408).

28 "A cadeia de custódia das provas, como instituto da teoria das provas apresentada ao longo do presente trabalho, também deve ser vista como um 
$5^{\circ}$, LIV, LV e LVII, CF), especialmente em relação aos meios de obtenção de prova levados a cabo valendo-se do fator "surpresa" (ex. interceptação telefônica ${ }^{29}$ e busca e a apreensão ${ }^{30}$ ), ou ainda elementos produzidos na fase inquisitorial, desde que sejam provas cautelares, não repetíveis e antecipadas $^{31}$ (art. 155, CPP).

A ideia de contraditório diferido pode ser compreendida na distinção entre contraditório sobre a prova e contraditório para a prova ${ }^{32}$, na primeira hipótese ter-se-ia a participação defensiva após a formação da prova enquanto na segunda o contraditório ocorreria na própria formação dela. De todo modo, é relevante consignar que o contraditório é premissa

direito subjetivo das partes, visto que a garantia de uma prova idônea e preservada é um desdobramento da garantia ao devido processo legal" (AZEVEDO, Yuri. A importância da cadeia de custódia das provas para o devido processo legal. In: PRADO, Geraldo; MALAN, Diogo (orgs). Ensaios sobre a cadeia de custódia das provas no processo penal brasileiro. Florianópolis: Empório do Direito, 2017, p. 106).

29 Sobre o tema da cadeia de custódia da prova no que tange às interceptações telefônica e sua regulamentação na legislação brasileira cf.: SANTORO, Antonio E. R.; TAVARES, Natália L. F.; GOMES, Jefferson C. O protagonismo dos sistemas de tecnologia da informação na interceptação telefônica: a importância da cadeia de custódia. Revista Brasileira de Direito Processual Penal, Porto Alegre, vol. 3, n. 2, p. 605-632, mai./ago. 2017.

30 Exemplo disso são as chamadas provas digitais (notebooks, hds, celulares e etc.) em relação às quais se afirma a necessidade de montar a cadeia de custódia da prova de modo que: "As provas digitais serão etiquetadas, documentadas e marcadas com as iniciais do perito, a hora e a data, o número do processo e dados de identificação. Cada passo da análise forense computacional deve ser documentado em detalhes” (TEIXEIRA, Tarcísio. Curso de direito e processo eletrônico: doutrina, jurisprudência e prática. $3^{\mathrm{a}}$ ed. São Paulo: Saraiva, 2015, p. 539).

31 Segundo Gustavo Badaró “a 'prova' irrepetível não é produzida nem submetida ao contraditório; a prova cautelar é produzida sem observância do contraditório, normalmente durante o inquérito policial, sendo posteriormente apenas submetida a contraditório judicial; as provas antecipadas, são produzidas em juízo, com contraditório antecipado, ainda que se esteja na fase do inquérito policial” (Processo Penal. 4a . ed. São Paulo: RT, 2016, p. 424).

32 A expressão é citada como slogan da reforma do Código de Processo Penal da Itália, visto que com a adoção do sistema acusatório, o contraditório, que no sistema anterior era exercido sobre a prova já produzida, passa a ser efetivado no momento exato da formação da prova (FERRUA, Paolo. Gênese da reforma constitucional do "giusto processo" na Itália. Revista Brasileira de Direito Processual Penal, Porto Alegre, vol. 3, n. 2, mai./ago. 2017, p. 667-668). 
fundamental do Estado Democrático de Direito, notadamente no âmbito das decisões penais, que afetam o estado de liberdade do indivíduo, somente se legitimando por um saber que possibilite o esclarecimento dos fatos sob a dupla ótica da sociedade e o do indivíduo ${ }^{33}$.

De outro lado, embora o Código de Processo Penal não contemple regulamentação específica sobre a documentação da cadeia de custódia da prova, Gustavo Badaró indica dispositivos legais do referido diploma que permitem a interpretação sistemática acerca de sua necessidade, exemplificando com o disposto no art. $6^{\circ}$, especialmente os incisos I e III, que disciplinam os atos de investigação atribuindo à autoridade policial o dever de dirigir-se ao local do crime "providenciando para que não se alterem o estado e conservação das coisas, até a chegada dos peritos criminais", assim como, colha "todas as provas que servirem para o esclarecimento do fato." ${ }^{34}$

Essas hipóteses ganham evidência porque o controle da prova pela defesa inevitavelmente dependerá da reconstrução da história do dado ou elemento probatório, viabilizando o conhecimento da fonte de prova e de como foi aportada aos autos da investigação, sem olvidar-se da imprescindibilidade do Estado garantir a "mesmidade" 35 e integridade da prova, para que possa ser acreditada ${ }^{36}$ no processo, conforme explicado no item predecessor.

Com isso, segundo Geraldo Prado, pretende-se discutir a possibilidade de manipulação indevida do elemento probatório, notadamente porque a cadeia de custódia da prova "constitui e, também interroga, no plano teórico, as condições concretas do melhor conhecimento judicial.”37

33 GOMES FILHO, Antonio Magalhães. Direito à prova no processo penal. São Paulo: RT, 1997, p. 55.

34 BADARÓ, Gustavo. A cadeia de custódia e sua relevância para a prova penal. In: SIDI, Ricardo; LOPES, Anderson B. Temas atuais da investigação preliminar no processo penal. Belo Horizonte: D’Plácido, 2018, p. 526.

35 PRADO, Geraldo. Op. cit, p. 16.

36 “O tema de provas exige a intervenção de regras de 'acreditação', pois nem tudo que ingressa no processo pode ter valor probatório, há que ser 'acreditado', legitimado, valorado desde sua coleta até a sua produção em juízo para ter valor probatório." (LOPES JR., Aury. Op. cit., p. 412.)

37 PRADO, Geraldo. Op. cit., p. 17. 
A discussão parte do pressuposto de que a incidência da presunção de inocência implica reconhecer a inversão da fé nos agentes estatais, impondo que o percurso do material probatório utilizado pela acusação precisa estar documentado com a indicação da apreensão, manuseio e análise, possibilitando a identificação do "nexo de causalidade entre o resultado pretendido e o caminho retrospectivo até a cena do crime"38.

Além do mais, o devido processo legal, a paridade de armas, a ampla defesa e o contraditório tornam essencial a manutenção da higidez da cadeia de custódia, como forma de possibilitar à defesa tratamento equânime ${ }^{39}$ ao conferido ao Ministério Público, propiciando o conhecimento integral daquilo que é imputado ao acusado, mas também a reação defensiva, postulando a produção das provas para esmorecer a tese acusatória ${ }^{40}$.

Com efeito, a cadeia de custódia inicia-se com o procedimento policial que detecta a existência de um vestígio, conforme dispõe a Portaria $n^{\circ} .82$, de 16 de julho de 2014 da Secretaria Nacional de Segurança Pública $^{41}$, a qual estabelece as diretrizes sobre os procedimentos a serem observados no tocante à cadeia de custódia de vestígios. Nesse contexto, a relevância da documentação cronológica da prova decorre da impossibilidade de "controlar os mecanismos de convencimento psicológico do juiz, o controle da decisão judicial em um Estado democrático de direito deve ser dar através de sistemas de controles epistêmicos, mediante

38 ROSA, Alexandre Morais da. Guia do Processo Penal Conforme a Teoria dos Jogos. $4^{\mathrm{a}}$. ed. Florianópolis: Empório do Direito, 2017, p. 446.

39 TJPR - $2^{\text {a }}$ C. Criminal - HCC- 1167881-4 - Jandaia do Sul - Rel.: Lilian Romero - Unânime - J. 10.04.2014.

40 Apelação Crime No 70066882929 , Terceira Câmara Criminal, Tribunal de Justiça do RS, Relator: João Batista Marques Tovo, Julgado em 26/11/2015.

41 Disponível em: <http://www.lex.com.br/legis_25740023_portaria_n_82_ de_16_de_julho_de_2014>. Acesso 12 ago. 2017. O Código de Processo Penal não regulamenta de forma direta a denominada cadeia de custódia, tratando, no máximo, de especificar a prova pericial e o exame de corpo de delito (arts. 158 a 184, CPP). Na América do Sul interessante registrar a previsão detalhada da matéria no ordenamento jurídico colombiano com destaque nos arts. 254 a 266 do Código de Procedimiento Penal. (Disponível em: <http://www.alcaldiabogota.gov.co/sisjur/normas/Norma1.jsp?i=14787>. Acesso em 08 dez. 2017. 
critérios objetivos, inclusive na fase da produção da prova, para garantir a qualidade da decisão judicial." ${ }^{42}$

Em outras palavras, o controle da decisão judicial passa inevitavelmente pela aferição da confiança da prova, isto porque "partindo da compreensão de um processo penal constitucional e convencionalmente decantado, toda e qualquer atividade probatória ou, caso prefiram, todo e qualquer ato praticado pela administração por intermédio de seus atores - funcionários públicos -, necessariamente demanda o inarredável controle epistêmico como fundamento e razão do próprio ato, ou seja, e por exemplo, a tese acusatória estampada em um processo criminal - e, com isso, todos os atos da administração - deve ser submetida a um teste de estresse, no qual se perquire a verificação e refutação, em provas e contraprovas." ${ }^{43}$

Para viabilizar a fiabilidade da prova a Portaria $\mathrm{n}^{\circ} .82$, de 16 de julho de 2014, da Secretaria Nacional de Segurança Pública, prevê expressamente a etapa externa e interna da cadeia de custódia, desde a chegada das autoridades estatais ao local do crime até a realização de perícia e eventual descarte do material, apontando-se como pertencente à etapa externa os seguintes passos (item 2.2 da portaria): a) preservação do local do crime; b) busca do vestígio; c) reconhecimento do vestígio; d) fixação do vestígio; e) coleta do vestígio; f) acondicionamento do vestígio; g) transporte do vestígio; h) recebimento do vestígio.

Por sua vez, a fase interna alcança todo o itinerário do vestígio, desde a entrada no órgão pericial até sua devolução ao órgão requisitante com o respectivo laudo pericial, abarcando: a) recepção e conferência do vestígio; b) classificação, guarda e/ou distribuição do vestígio; c) análise pericial propriamente dita; d) guarda e devolução do vestígio da prova; e) guarda de vestígios para contraperícia; f) registro da cadeia de custódia.

Essa regulamentação, pouco explorada na doutrina, é relevante porque, segundo estudo específico acerca da matéria, basicamente, três

42 MORAES, Ana Luisa Zago de. Prova penal: da semiótica à importância da cadeia de custódia. Revista Brasileira de Ciências Criminais, São Paulo, vol. 132, p. 117-138, jun./2017, p. 136.

43 FELIX, Yuri. Fiabilidade da prova e a cadeia de custódia: um imperativo democrático (jurisprudência anotada). Boletim IBCCRIM, São Paulo, ano 25, $\mathrm{n}^{\circ}$ 299, out. 2017, p. 2054. 
tipos de argumentos podem ser desenvolvidos pela defesa para questionar a cadeia de custódia: a) falsidade da prova; b) insuficiência da prova da cadeia de custódia da prova; e c) falsidade da prova da cadeia de custódia da prova, sendo que o primeiro e terceiro argumentos se resolvem, normalmente, com incidente de falsidade documental, permanecendo as maiores controvérsias no que diz respeito ao assunto indicado no item "b"

Com base nessas premissas, passa-se a discutir então quando será exigível a prova da cadeia de custódia, ou seja, a documentação da cronologia de determinado elemento probatório. Destarte, o exemplo apresentado cuida da seguinte hipótese: "quando a droga é apreendida, deve ser embalada (se já não estiver), lacrada e identificada. Esse recipiente pode passar por várias pessoas. Contanto que a integridade do recipiente seja mantida, mediante aposição de lacre, é possível concluir, de forma razoável, que a droga ali acondicionada é a mesma que foi originalmente apreendida. Nessas hipóteses é que ganha destaque a comprovação da cadeia de custódia." ${ }^{45}$

Por conseguinte, para identificar-se a preservação da cadeia de custódia da prova é imprescindível a garantia de acesso aos elementos de prova documentados nos autos do procedimento persecutório penal, tendo o Supremo Tribunal Federal se debruçado em inúmeras oportunidades a respeito da matéria a ponto de consolidar a súmula vinculante $14^{46}$, que garante ao defensor a possibilidade conhecer os elementos angariados em desfavor de seu constituinte.

A partir daí, tem-se que a compreensão do STF sobre o acesso à prova pela defesa constitui vetor de controle da cadeia de custódia da prova, especialmente para permitir à defesa o conhecimento das fontes probatórias, concebendo que "qualquer tipo de filtro realizado na prova

44 DALLAGNOL, Deltan Martinazzo; CÂMARA, Juliana de Azevedo Santa Rosa. A cadeia de custódia da prova. In: SALGADO, Daniel de Resende; QUEIROZ, Ronaldo Pinheiro de (orgs.). A prova no enfrentamento à macrocriminalidade. $2^{a}$. ed. Salvador: Juspodivm, 2016, p. 437.

45 Idem, ibidem.

46 "É direito do defensor, no interesse do representado, ter acesso amplo aos elementos de prova que, já documentados em procedimento investigatório realizado por órgão com competência de polícia judiciária, digam respeito ao exercício do direito de defesa.” 
- quer seja por ocultação, destruição ou agregação de conteúdo -, é incompatível com o 'acesso amplo aos elementos de prova', justamente por corresponder à parte de um todo." ${ }^{47}$

Logo, a defesa "tem o direito de conhecer a totalidade dos citados elementos informativos para rastrear a legalidade da atividade persecutória, pois de outra maneira não haveria como identificar provas ilícitas" ${ }^{48}$, o que permite à defesa repudiar eventuais excessos acusatórios e preparar-se para produzir a respectiva contraprova ${ }^{49}$. A questão do acesso à totalidade do material probatório angariado na fase investigatória é ressaltada quando se compreende que "o exame da legalidade da investigação criminal concentrado com exclusividade no material apresentado pelo acusador em juízo é, de regra, inócuo ou no mínimo insuficiente." ${ }^{50}$ Desse modo, os princípios constitucionais limitadores do poder punitivo estatal, as normas processuais penais e a jurisprudência nacional possibilitam o reconhecimento da cadeia de custódia como mecanismo hábil a conferir fidelidade à prova, permitindo o conhecimento pela defesa de eventual manipulação, adulteração ou supressão da prova provocando consequências que serão devidamente examinadas no tópico subsequente.

47 MACHADO, Vitor Paczek; JEZLER JUNIOR, Ivan. A prova eletrônica-digital e a cadeia de custódia das provas: uma (re)leitura da Súmula Vinculante 14. Boletim IBCCRIM, São Paulo, ano 24, nº 288, nov./2016, p. 8-9.

48 PRADO, Geraldo. Prova penal e sistema de controles epistêmicos: a quebra da cadeia de custódia das provas obtidas por métodos ocultos. São Paulo: Marcial Pons, 2014, p. 41.

49 “Não se pode confundir, igualmente, prova contrária com outra expressão própria do léxico processual, que é a contraprova. Com esta, indica-se qualquer prova apresentada por uma parte, com o propósito de refutar os elementos apresentados pelo adversário. Trata-se aqui do fenômeno que não se liga à relação entre fato e prova, mas à própria natureza contraditória do processo, que exige o reconhecimento, dentre outros, de um direito à prova, que inclui, evidentemente, a prerrogativa de contrapor provas às apresentadas pela parte contrária, com o objetivo de influir no convencimento do juiz." (GOMES FILHO, Antonio Magalhães. Notas sobre a terminologia da prova (reflexos no processo penal brasileiro). In: YARSHELL, Flávio Luiz; MORAES, Maurício Zanoide de (orgs). Estudos em homenagem à professora Ada Pellegrini Grinover. São Paulo: DPJ Editora, 2005, p. 314).

50 PRADO, Geraldo. Prova penal e sistema de controles epistêmicos: a quebra da cadeia de custódia das provas obtidas por métodos ocultos. São Paulo: Marcial Pons, 2014, p. 48. 


\section{A ILICITUde DA PROVA EM DECORRÊNCIA DA QUEBRA DA CADEIA DE CUSTÓDIA}

A partir do que foi explorado nos tópicos anteriores, faz-se necessário o exame acerca das consequências da quebra da cadeia de custódia, visto que apesar da falta de legislação sobre o tema, sem prejuízo da norma administrativa existente que orienta a atividade das autoridades legais, é possível apontar potenciais repercussões trabalhando-se com os princípios constitucionais. Nessa linha de pensamento, assinala Aury Lopes Junior que "a cadeia de custódia exige o estabelecimento de um procedimento regrado e formalizado, documentando toda a cronologia existencial daquela prova, para permitir posterior validação em juízo e exercício do controle epistêmico."

Assim, é obrigação do Estado garantir a todo e qualquer acusado que as provas obtidas por meio da persecução penal sejam devidamente acondicionadas, custodiadas e posteriormente periciadas, até mesmo para possibilitar o contraditório diferido sobre elas ou se autorizar o questionamento sobre a credibilidade da prova. A afirmação é importante para que se compreendam as consequências legais, em especial sua fundamentação jurídica, advindas da exigência a respeito da cronologia existencial imposta à prova, até mesmo como forma de se incentivar a postura mais correta às autoridades legais, bem como oferecer aos acusados o devido processo legal, pautado no respeito às garantias constitucionais.

Sobre a problemática enfrentada no tocante à cadeia de custódia, pense-se, a título de exemplo, no caso que em que há fundadas dúvidas sobre a identidade da prova, ou seja, se a prova apreendida pela autoridade investida é a mesma trazida aos autos, ou, então, sobre a sua credibilidade, decorrente da falta de documentação na apreensão da prova. Com efeito, o desrespeito aos procedimentos mencionados acima deve acarretar consequências que serão examinadas à luz da ilicitude da prova.

Aliás, a perspectiva da ilicitude da prova é adotada em razão da impossibilidade de se refazer o caminho empregado no meio de investigação que resultou na obtenção da prova, de modo que não seria possível

51 LOPES Jr., Aury. Direito Processual Penal. 14a . ed. São Paulo: Saraiva, 2017, p. 412 . 
praticar o ato investigativo/probatório novamente ${ }^{52}$. Sob esse viés não há que se falar em problemas de nulidade e/ou valoração, mas sim de terminante exclusão do material com todas as suas consequências de não conhecimento pelo magistrado.

Estabelecendo um elo entre o tema da cadeia de custódia e ilicitude probatória, Geraldo Prado argumenta que "o filtro processual contra provas ilícitas depende do rastreio das provas às fontes de prova (elementos informativos) e a ilicitude probatória, direta ou por derivação, é mais facilmente detectável na sequência deste rastro produzido entre as fontes de provas e os elementos (meios) probatórios propriamente ditos." ${ }^{53}$ Como é de conhecimento, a Constituição Federal prevê em seu art. 5, LVI, a inadmissibilidade das provas obtidas por meios ilícitos. Além disso, o Código de Processo Penal, por meio de reforma operada no ano de 2008, reproduziu o dispositivo constitucional ao estabelecer o mesmo regramento em seu art. 157.

Nos casos narrados acima, a falta de cronologia acerca da existência da prova faz com que não mais se possa falar na confiabilidade daquele material, seja na perspectiva de sua existência ou do manuseio pelas autoridades legais, impedindo, por consequência, que o acusado tenha a possibilidade de desempenhar o exercício da defesa à luz de toda a principiologia constitucional. Se houve a quebra da cadeia de custódia e, por consequência, a perda da credibilidade da prova, que ao ser apreendida, por exemplo, não foi acondicionada de forma adequada, ela será considerada ilícita ${ }^{54}$.

Como ensina Carlos Edinger, "a prova cuja cadeia de custódia for quebrada será considerada ilícita ou ilegítima (distinção que, para mim, cientificamente, a partir da supremacia da Constituição ou da sua dimensão objetiva, pouco sentido faz). Assim, "uma vez reconhecida sua ilicitude, de forma definitiva, haverá o desentranhamento e sua inutilização." ${ }^{55}$ Aury

52 GOMES FILHO, Antonio Magalhães. Notas sobre a terminologia da prova (reflexos no processo penal brasileiro). In: YARSHELL, Flávio Luiz; MORAES, Maurício Zanoide de (orgs). Estudos em homenagem à professora Ada Pellegrini Grinover. São Paulo: DPJ Editora, 2005, p. 310.

54 Ibidem, p. 82.

EDINGER, Carlos. Op. cit., p, 251. 
Lopes Junior apresenta relevante indagação inteiramente pertinente com o presente ensaio: "qual a consequência da quebra a cadeia de custódia (break on the chain of custody)?", respondendo que "sem dúvida deve ser a proibição de valoração probatória com a consequente exclusão física dela e de toda a derivada" 56 .

De qualquer forma, observa-se que a cadeia de custódia violada gerará a exclusão do material probatório colhido sem o respeito aos procedimentos legais existentes, de modo que naturalmente não poderá ser objeto de qualquer valoração pelo magistrado ${ }^{57}$. Além disso, deve-se examinar, ainda, quais eventuais provas decorrentes daquela considerada ilícita deverão ser excluídas do processo $^{58}$, sem a possibilidade de emprego, comprovando-se a diligência que deve ser empregada pelas autoridades legais em relação à prova. Conforme Lopes Jr. e J. Gloeckner "acolhendo-se a doutrina da contaminação dos frutos da árvore envenenada - fruits of the poisonous tree -, necessariamente teremos de reconhecer que as provas ilícitas (inclusive por derivação) devem ser consideradas nulas independentemente do momento em que foram produzidas." ${ }^{59}$

Diante disso, sobrevindo a quebra da cadeia de custódia da prova, ou seja, a inexistência ou imprecisão na reconstrução do dado ou elemento probatório levará à conclusão de que se trata de prova ilícita ${ }^{60}$, nos termos do art. $5^{\circ}$, LVI, da Constituição Federal e art. 157 do Código

56 LOPES JR., Aury. Direito Processual Penal. 14ª . ed. São Paulo: Saraiva, 2017, p. 414.

57 GOMES FILHO, Antonio Magalhães. Direito à prova no processo penal. São Paulo: RT, 1997, p. 107/108.

58 PRADO, Geraldo. Op. cit., p. 91.

59 LOPES JR., Aury; GLOECKNER, Ricardo J. Investigação preliminar no processo penal. $5^{\text {a }}$ ed. São Paulo: Saraiva, 2013, p. 349.

60 Em sentido oposto às conclusões obtidas nesse estudo, Gustavo Badaró entende que a quebra da cadeia de custódia não implica ilicitude da prova, devendo o problema ser resolvido no momento da valoração da prova, advertindo que mesmo nos casos mais graves, em que se tenham dúvidas sobre a autenticidade e integridade da prova, isso repercutirá no seu valor, incumbindo ao julgador esta análise. (BADARÓ, Gustavo. A cadeia de custódia e sua relevância para a prova penal. In: SIDI, Ricardo; LOPES, Anderson B. Temas atuais da investigação preliminar no processo penal. Belo Horizonte: D’Plácido, 2018, p. 535). 
de Processo Penal, e a necessidade de exclusão física. Por fim, caso se verifique que os elementos probatórios produzidos posteriormente guardam direta e imediata vinculação com a prova obtida mediante violação à cadeia de custódia da prova, subsistirá o vício originário que contaminará todos os elementos informativos oriundos da atividade persecutória do Estado $^{61}$.

\section{Conclusão}

Este estudo pretendeu apresentar o significado da cadeia de custódia, compreendida pela necessidade de historiar toda a cronologia de determinado vestígio utilizado como prova no processo penal e, com base nisso, identificar sua presença no ordenamento jurídico brasileiro, oportunidade na qual se verificou sua íntima relação com os postulados da paridade de armas, presunção de inocência, devido processo legal, ampla defesa e contraditório (art. 5, LIV, LV e LVII, CF).

Uma das manifestações mais importantes da cadeia de custódia no arcabouço jurídico pátrio deu-se por meio da Portaria 82, de 16 de julho de 2014, da Secretaria Nacional de Segurança Pública, mormente porque delimitou com precisão mecanismo de segurança para resguardar a cadeia de custódia da prova, iniciando-se na sua coleta na cena do crime até a entrega do laudo pericial e eventual descarte. Trata-se de normativa que indubitavelmente deve servir de parâmetro para as autoridades incumbidas da investigação criminal, como forma de tutelar a "mesmidade" da prova, ou seja, que o elemento probatório utilizado no processo criminal é efetivamente aquele encontrado na cena do crime, assim como superar a "desconfiança" de que não houve alteração ou manipulação indevida do vestígio.

61 "Como foram consideradas ilícitas as provas colhidas, adotou a teoria dos frutos da árvore envenenada (os vícios da árvore são transmitidos aos seus frutos) para anular a ação penal desde o início, apontando que assim se posicionam a doutrina e a jurisprudência - uma vez reconhecida a ilicitude das provas colhidas, essa circunstância as torna destituídas de qualquer eficácia jurídica, sendo que elas contaminam a futura ação penal." (STJ - HC 149.250SP, Rel. Min. Adilson Vieira Macabu (Desembargador convocado do TJ-RJ), julgado em 7/6/2011). 
Não se olvidou ainda da análise jurisprudencial do assunto, precipuamente a leitura da súmula vinculante $\mathrm{n}^{\circ} 14$ como instrumento para garantir o conhecimento pela defesa, sobre as fontes de prova existentes em desfavor do acusado, conferindo-se interpretação consentânea à preservação da integridade e higidez do elemento probatório.

Com isso, concluiu-se que nem toda prova é aquilo que a parte afirma ser, o que somente será concretizado por meio de mecanismo de “acreditação", realizando-se verdadeira filtragem para efetuar o controle de confiabilidade da prova, possibilitando ao acusado conhecer tudo que foi produzido em seu desfavor, mas também a efetiva reação, com igualdade de meios e oportunidades àqueles conferidos à acusação.

Diante disso, retoma-se o problema que guiou este artigo: qual a consequência que a inobservância dos procedimentos legais ou do devido cuidado no momento da coleta, manipulação e transporte do objeto pode trazer para o elemento, que agora é prova, trazido em juízo? Assim, deve-se verificar as consequências jurídicas oriundas da quebra da cadeia de custódia da prova entendendo-se como adequada e harmônica a Constituição Federal a compreensão de ilicitude probatória, enodando todos os elementos derivados, conforme a teoria dos frutos da árvore envenenada.

\section{REFERÊNCIAS}

AZEVEDO, Yuri. A importância da cadeia de custódia das provas para o devido processo legal. In: PRADO, Geraldo; MALAN, Diogo (orgs.). Ensaios sobre a cadeia de custódia das provas no processo penal brasileiro. Florianópolis: Empório do Direito, 2017. p. 25-121.

BADARÓ, Gustavo. A cadeia de custódia e sua relevância para a prova penal. In: SIDI, Ricardo; LOPES, Anderson B. Temas atuais da investigação preliminar no processo penal. Belo Horizonte: D’ Plácido, 2018. p. 517-538.

BADARÓ, Gustavo. Processo Penal. 4ª ed. São Paulo: RT, 2016.

CAPEZ, Fernando. Curso de processo penal. 19ª ed. São Paulo: Saraiva, 2012.

CARVALHO, Jeferson Lemes. Cadeia de Custódia e Sua Relevância na Persecução Penal. Brazilian Journal of Forensic Sciences, Medical Law and Bioethics, vol. 5, p. 371-382, 2016. http://dx.doi.org/10.17063/bjfs5(4)y2016371 
DALLAGNOL, Deltan Martinazzo; CÂMARA, Juliana de Azevedo Santa Rosa. A cadeia de custódia da prova. In: SALGADO, Daniel de Resende; QUEIROZ, Ronaldo Pinheiro de (orgs.). A prova no enfrentamento à macrocriminalidade. $2^{\mathrm{a}}$. ed. Salvador: Juspodivm, 2016. p. 435-471.

DIAS FILHO, Claudemir Rodrigues. Cadeia de custódia: do local de crime ao trânsito em julgado; do vestígio à evidência. In: MOURA, Maria Thereza Rocha de Assis; NUCCI, Guilherme de Souza (orgs). Doutrinas Essenciais - Processo Penal. v. 3. São Paulo: RT, 2012. p. 393-408.

EDINGER, Carlos. Cadeia De Custódia, Rastreabilidade Probatória. Revista Brasileira de Ciências Criminais, vol. 120, p. 237-257, mai.-jun./2016.

FELIX, Yuri. Fiabilidade da prova e a cadeia de custódia: um imperativo democrático (jurisprudência anotada). Boletim IBCCRIM, São Paulo, ano 25, n 299 , out./2017, p. 2054.

FERRUA, Paolo. Gênese da reforma constitucional do "giusto processo" na Itália. Revista Brasileira de Direito Processual Penal, Porto Alegre, vol. 3, n. 2, p. 661-688, mai./ago. 2017. https://doi.org/10.22197/rbdpp.v3i2.61

GOMES FILHO, Antonio Magalhães. Direito à prova no processo penal. São Paulo: RT, 1997.

GOMES FILHO, Antonio Magalhães. Notas sobre a terminologia da prova (reflexos no processo penal brasileiro). In: YARSHELL, Flávio Luiz; MORAES, Maurício Zanoide de (orgs). Estudos em homenagem à professora Ada Pellegrini Grinover. São Paulo: DPJ Editora, 2005, p. 303-318.

LOPES JR., Aury. Direito Processual Penal. 14a . ed. São Paulo: Saraiva, 2017.

LOPES JR., Aury; GLOECKNER, Ricardo J. Investigação preliminar no processo penal. $5^{\mathrm{a}}$ ed. São Paulo: Saraiva, 2013.

LOPES JR., Aury; ROSA, Alexandre Morais da. A importância da cadeia de custódia para preservar a prova penal. Disponível em: <https://www.conjur.com.br/2015jan-16/limite-penal-importancia-cadeia-custodia-prova-penal >. Acesso em: 08 dez. 2017.

MACHADO, Vitor Paczek; JEZLER JUNIOR, Ivan. A prova eletrônica-digital e a cadeia de custódia das provas: uma (re)leitura da Súmula Vinculante 14. Boletim IBCCRIM, São Paulo, ano 24, nº 288, p. 8-9, nov./2016.

MORAES, Alexandre de. O devido processo legal e a vedação às provas ilícitas. Disponível em: <https://www.conjur.com.br/2014-abr-11/justica-comentadadevido-processo-legal-vedacao-provas-ilicitas>. Acesso em: 08 dez. 2017. 
MORAES, Ana Luisa Zago de. Prova penal: da semiótica à importância da cadeia de custódia. Revista Brasileira de Ciências Criminais, São Paulo vol. 132, p. 117138, jun./2017.

NUNES, Dierle José Coelho. O princípio do contraditório: uma garantia de influência e de não surpresa. In: DIDIER JR, Fredie. (org.). Teoria do Processo - Panorama doutrinário mundial. 1 ed. Salvador: Juspodium, 2007, v.1, p. 151-174.

PRADO, Geraldo. Prova penal e sistema de controles epistêmicos: A quebra da cadeia de custódia das provas obtidas por métodos ocultos. São Paulo: Marcial Pons, 2014.

PRADO, Geraldo. Ainda sobre a "quebra da cadeia de custódia das provas". Boletim IBCCRIM, São Paulo, ano 22, nº 262, p. 16-17, set./2014.

ROSA, Alexandre Morais da. Guia do Processo Penal Conforme a Teoria dos Jogos. $4^{\mathrm{a}}$. ed. Florianópolis: Empório do Direito, 2017.

SANTORO, Antonio E. R.; TAVARES, Natália L. F.; GOMES, Jefferson C. O protagonismo dos sistemas de tecnologia da informação na interceptação telefônica: a importância da cadeia de custódia. Revista Brasileira de Direito Processual Penal, Porto Alegre, vol. 3, n. 2, p. 605-632, mai./ago. 2017. https://doi.org/10.22197/ rbdpp.v3i2.76

TEIXEIRA, Tarcísio. Curso de direito e processo eletrônico: doutrina, jurisprudência e prática. $3^{\mathrm{a}}$ ed. São Paulo: Saraiva, 2015. 


\section{Informações adicionais e declarações dos autores (integridade científica)}

Declaração de conflito de interesses (conflict of interest declaration): os autores confirmam que não há conflitos de interesse na realização das pesquisas expostas e na redação deste artigo.

Declaração de autoria e especificação das contribuições (declaration of authorship): todas e somente as pessoas que atendem os requisitos de autoria deste artigo estão listadas como autores; todos os coautores se responsabilizam integralmente por este trabalho em sua totalidade.

- Isabela Aparecida de Menezes: projeto e esboço inicial, revisão bibliográfica, redação, revisão crítica com contribuições substanciais, aprovação da versão final;

- Luiz Antonio Borri: projeto e esboço inicial, revisão bibliográfica, redação, revisão crítica com contribuições substanciais, aprovação da versão final;

- Rafael Junior Soares: projeto e esboço inicial, revisão bibliográfica, redação, revisão crítica com contribuições substanciais, aprovação da versão final.

Declaração de ineditismo e originalidade (declaration of originality): os autores asseguram que o texto aqui publicado não foi divulgado anteriormente em outro meio e que futura republicação somente se realizará com a indicação expressa da referência desta publicação original; também atestam que não há plágio de terceiros ou autoplágio. 
Dados do processo editorial

(http://www.ibraspp.com.br/revista/index.php/RBDPP/about/editorialPolicies)

- Recebido em: 17/12/2017

Equipe editorial envolvida

- Controle preliminar e verificação de plágio: 19/12/2017

- Avaliação 1: 01/01/2018

- Avaliação 2: 06/01/2018

- Editor-chefe: 1 (VGV)

- Editor-associado: 1 (GHB)

- Revisores: 4

- Avaliação 3: 07/01/2018

- Avaliação 4: 08/01/2018

- Decisão editorial preliminar: 12/01/2018

- Retorno rodada de correções 1: 31/01/2018

- Decisão editorial preliminar 2: 31/01/2018

- Retorno rodada de correções 2: 31/01/2018

- Decisão editorial final: 01/02/2018

\section{COMO CITAR ESTE ARTIGO:}

MENEZES, Isabela A.; BORRI, Luiz A.; SOARES, Rafael J. A quebra da cadeia de custódia da prova e seus desdobramentos no processo penal brasileiro. Revista Brasileira de Direito Processual Penal, Porto Alegre, vol. 4, n. 1, p. 277-300, jan./abr. 2018. https://doi.org/10.22197/rbdpp.v4i1.128

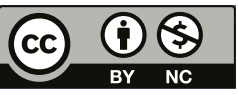

Esta obra está licenciada com uma Licença Creative Commons Atribuição-NãoComercial 4.0 Internacional. 